\title{
Dos voces afrocolombianas en dos mares
}

\author{
Two Afro-Colombian voices in two seas
}

\author{
Alfredo Vanín \\ Universidad del Cauca \\ alfredovanin@gmail.com
}

Las voces afrocolombianas en el arte, la literatura, la ciencia, la academia y la vida cotidiana, no han terminado de ser reconocidas al interior de un país que inició su vida republicana con la pesada herencia del colonialismo racista y hegemónico. Hablo de todas las voces, incluidas aquellas que no tuvieron las posibilidades de moldearse en las escuelas y academias, pero continuaron un legado importante en la formación de la palabra y el pensamiento afrocolombianos.

Una de las particularidades geográficas más relevantes de Colombia es la presencia de dos mares, dos regiones diferentes pero conectadas en su historia. El Caribe recibió todo el peso de la conquista en sus inicios, y el Pacífico se convirtió en el territorio de extracción aurífera por excelencia, con las minas ubicadas a lo largo de su territorio y la explotación de la mano de obra esclavizada. Ambas regiones tuvieron los aportes de la mano de obra y la creatividad cultural de los afrodescendientes, quienes dejaron, entre otros, dos grandes legados: el territorio de libertad del Palenque de la Matuna y un nuevo idioma, el palenquero.

El Caribe fue el punto de partida de la construcción de la nacionalidad. Más tarde, fue desplazado por el interior del país, en una decisión que alejó a la nación del mar como el espacio primordial del desarrollo 
económico e institucional, utilizando, en cambio, la zona andina como punto de asiento del gobierno central, en una ubicación nada estratégica frente al mundo, que ahora debemos reconocer como equivocada.

Lo anterior nos sirve de sustento para entender dos voces literarias que son altamente representativas no solo de las dos regiones mencionadas sino del país entero, aunque de alguna manera ambas hayan sido poco estudiadas y divulgadas en la academia nacional. Me refiero al narrador, ensayista y activista por los derechos afrocolombianos, el caribeño Manuel Zapata Olivella (Lorica, 1920 - Bogotá, 2004) y al poeta, narrador y político del Pacífico, Helcías Martán Góngora (Guapi, 1920 - Cali, 1983), coincidentemente nacidos en el mismo año. Dos voces afrocolombianas del pensamiento y la literatura que cruzaron sus líneas del Caribe hacia el Pacífico y del Pacífico al Caribe y al mundo, siendo reconocidos en diferentes lugares del planeta.

Para el momento de sus nacimientos, el mundo ha visto la insurgencia de las Antillas y del África negra: el Congo y Argelia se sublevan contra sus dominadores europeos. Los dos escritores recibirán la influencia decisiva de pensadores y escritores africanos y afroantillanos que calarán hondo en su ideario. Tendrán como antecesores y contemporáneos, entre otros, al poeta Léopold Sédar Senghor (Senegal, 1906 - Francia, 2000), a Frantz Fanon (Martinica, 1925 - Maryland, EE. UU. 1951) y al martiniqués Aimé Césaire (1913-2008), que publicará su Cuaderno de retorno a un pais natal; y ambos serán casi contemporáneos del poeta Derek Walcott, Premio Nobel de Literatura en 1992, nacido en Santa Lucía en 1930 y fallecido en Gros Islet, en 2017.

En Colombia, habían surgido las voces literarias y políticas de Diego Luis Córdoba (Neguá, 1907 -Ciudad de México, 1964), Natanael Díaz (Puerto Tejada, 1919 - 1964), Teresa Martínez de Varela (Quibdó, 1913 - 1998) y Marino Viveros (Puerto Tejada, 1922 - 2008), entre otras. En los años setenta, se percibían aún con fuerza las influencias de los movimientos negros del Black Power de los Estados Unidos y las voces de sus líderes. El mundo se llenó de voces negras, peinados afro y solidaridad con sus hombres y mujeres asesinados y atropellados en el sur de Estados Unidos; una práctica que no se ha extinguido y que, por el contrario, ha cobrado en la actualidad nuevas víctimas con un presidente surgido de la peor maleza financiera y el odio supremacista. 
Una de las oprobiosas diferencias en la historiografía y el canon literario colombiano es que mientras los escritores del centro del país en los ańos cuarenta fueron divulgados ampliamente -entre ellos la generación de Piedra y Cielo-, los escritores de los litorales, fueron muy poco difundidos. Algunos escritores negros encontraron en la revista Espiral un espacio para su divulgación, según nos dice Alberto Bejarano:

Es muy relevante descubrir el lugar primordial que tuvieron los autores del Pacífico colombiano en la revista Espiral, en una época en la cual esto era extremadamente raro en Colombia. Espiral incluye una variedad amplia de escritores y artistas del Valle del Cauca y el Pacífico como Enrique Buenaventura, Helcías Martán Góngora, Arnoldo Palacios, Alberto Dow, Natanael Díaz, Carlos López Narváez, Guillermo Payán Archer, Hernando Tejada, Lucy Tejada, Carlos Arturo Truque, Álvaro Sanclemente (53).

Sin embargo, han sido siempre las regiones las que han marcado el hito literario en el país: citemos casos como el de Jorge Isaacs, el "Tuerto" López, Candelario Obeso, Álvaro Mutis y García Márquez, entre otros. La época en la que crecen estos autores produjo un caldo de cultivo en el que se nutrieron voces que, además de enfrentar el futuro político, sedujeron con sus relatos y poemas, que implicaron una nueva manera de mirar la cultura y los aportes afrocolombianos a la vida y al ideario político de nuestro país, que, como muchos otros, se ha distinguido por negar los aportes negros e indígenas en la construcción nacional.

Helcías Martán fue un hombre que bebió de la lírica española del Siglo de Oro y que se nutrió, a la vez, de la poesía negra que tenía grandes representantes en el Caribe y en los Estados Unidos.

Manuel Zapata Olivella se hizo la gran pregunta: ¿qué nos une con África? Su tenacidad y su pasión vagabunda le dieron la respuesta. Es conmovedora la anécdota con el presidente senegalés Sédar Senghor, que narra en La rebelión de los genes. Le pidió al presidente que le dejara dormir desnudo una noche en una de las "factorías" donde habían dormido sus antepasados negros antes de ser embarcados hacia América. El presidente, de manera irresponsable, dijo Manuel Zapata Olivella, accedió, y luchó toda la noche con el remordimiento. Pero abrió las puertas de las "factorías de negros" al rumor que marcaría un hecho extraordinario: el escritor Zapata Olivella despertó en la mañana 
convencido de haber encontrado la ruta de escritura de Changó, el gran putas, un legado de su pluma y de su pensamiento que nos permitió ligar de manera sublime a los dos continentes, mediante la magia de la literatura y de la religión yoruba que perdura en América. El autor, a su vez, había vagabundeado por el Caribe y por el Pacífico, se había codeado en Harlem con hombres y mujeres negros, con seres errantes y doctos que sostenían a costa de sus vidas no solo la palabra, sino los idearios de la insurgencia negra. Zapata Olivella había adquirido el bagaje suficiente para que su epopeya surgiera untada de toda la carga mítica, con la sangre y el rumor de todos los que cruzaron el océano y de los que se quedaron esperando el regreso de sus congéneres. Y fue él quien no solo trazó la línea que uniría en la literatura a África con América, sino que también trazó el encuentro del Pacífico con el Caribe colombianos. Una ruta forzosa de los antepasados negros de la Nueva Granada, que, a su vez, nos enseñó el desastre impuesto por los colonizadores y sus descendientes en la conformación arbitraria de las comunidades y pueblos colombianos, donde se anquilosaron jerarquías insensatas, que, pese a su labor destructora, mantienen su poder seductor y violento en la destrozada nación colombiana.

La lírica de Helcías Martán se nutre de los clásicos españoles como del habla y la belleza del territorio y sus mujeres. Hijo y nieto de comerciantes y armadores de barcos, tuvo una estrecha relación con los orilleros del Pacífico, y desde su Guapi natal sostenía correspondencia con escritores de allende el mar, adonde fue a estudiar y, junto a paisanos contertulios, creó la revista Vanguardia, en la que traducía a poetas franceses y mostraba el acontecer de la vanguardia política y literaria del mundo. Sus momentos están a la par con los inolvidables escritores Carlos Arturo Truque, Arnoldo Palacios, Jorge Artel y Hugo Salazar Valdés. Y también con esa adorable poeta del Caribe, Meira del Mar, con quien mantuvieron una correspondencia literaria. A ambos autores los une el llamado que empieza con los que reclaman presencia política, ahora reconocibles en jóvenes artistas y profesionales, hombres y mujeres, que tienen en su voz la rebeldía antirracista y descolonizadora. Voces de hombres y mujeres que surgieron en la mitad del siglo XX y que recorrieron el mundo con sus versos y sus reclamaciones de igualdad en un mundo donde parecía que esto era imposible. 
Para entender a nuestros dos personajes, no solo es necesario revisar bibliotecas, sino también sentir las voces de las mujeres y hombres anónimos que impulsaron sus palabras y están transfigurados en sus relatos y poemas. A Helcías lo conmovió un canto de arrullo navideño escuchado en su niñez, que a veces repetía con dos anisados encima: "A la madrina del niño/ Díganle que digo yo/ Que si no tenía bebida/ Para que me convidó”.

Humano litoral, de Helcías, es el eco de otra voz importante y fundadora: humanizar el litoral fue en el sentido de "hacer litoral" al ser humano, parafraseando el pionero e inolvidable texto del, también guapireńo, Sofonías Yacup (Guapi, 1895-Cali, 1947). Aunque sea un poema amoroso o decididamente reivindicativo del paisaje, el poema 4 del Evangelio de la doncella tiene unas líneas que muestran tímidamente las intenciones que proponemos entre ambos escritores y sus contemporáneos: "Íbamos por la misma senda/ Nos conocíamos pero nos ignorábamos. Y mudos, impasibles, seguíamos por el camino como si fuéramos extraños" (92).

Zapata Olivella dedicó parte de su vida a enaltecer y difundir el canto de las mujeres de la llanura caribeña en el fandango, al que promovió por medio mundo, en llave con su hermana y artista Delia Zapata Olivella, sin la cual no habría construido ese mundo sólido de lo negro en el mundo. Y, mientras estudiaba los ritmos caribeños, divulgaba al mundo las glorias perdidas: Louis Armstrong frente a su público negro de Harlem, y, en general, el mundo afro de Estados Unidos y de las Antillas, mediante sus luchadores, artistas y poetas.

Al otro lado del país, Helcías saludaba también a cantantes negros, entre ellos, a la gran contralto afrocanadiense Portia White, a quien dedica un poema, y a los músicos y danzarinas negros del Pacífico, con un fervor que recorre lo más intenso de su poesía: "Me hacía guiños tu fugaz cintura/ negra negrura de la negrería./ Era en Buenaventura y una salvaje melodía/ trenzaba tu alegría y destrenzaba mi amargura” (Martán 139).

Nuestros dos artistas representan voces que se encuentran en un momento en el que las luchas descolonizadoras y la exaltación de lo negro cobran una fuerza que se prolonga en la actualidad, gracias a los pioneros. Entre ellos, los dos que lanzamos a estas páginas, quienes, a 
su vez, asumen herencias en explosión en su momento, indignados por los crímenes del Ku Klux Klan y las leyes segregacionistas del Tío Sam.

Del Pacífico al Caribe, el puente se tendió en pleno comercio esclavista, cuando las haciendas del Valle del río Cauca y las minas de oro del Pacífico lo requirieron. Una época de infamias que dejan su legado, pero que los descendientes negros han reinventado con honor en sus luchas desde la colonia hasta la actualidad. Hombres y mujeres que los dos escritores han enaltecido en sus estudios, narraciones y poemas, con herederos que escriben textos de alto vuelo basados en la herencia esclavista y libertaria, como La ceiba de la memoria del también caribeño Roberto Burgos Cantor.

Helcías es la voz lírica que levanta el vuelo en la llanura húmeda del Pacífico; Manuel, en la llanura seca del Caribe. Ambos apertrechados de una universalidad que los llevó a adentrarse en el mundo de los modernos palenques negros en busca de voz propia. La que nos han legado para continuar una canción, un texto, un poema que refleje nuestras voces y muestre al mundo las crecientes verdades que se descubren en nuevos herederos: desde las orillas del Guapi, los mares de Tumaco y Buenaventura, las errancias de los que he llamado "los Ulises negros", los polizones, las voces jóvenes de mujeres y hombres afro que interpelan al establecimiento y su hegemonía cada vez más en crisis.

Coincidentemente, los conocí a ambos. A Helcías lo traté durante años, en jornadas de poesía y bohemia inolvidables. Publicó un poema mío en Esparavel, su revista de los años setenta. A Zapata Olivella, cuando yo era un niño en Guapi, mientras rodaba un documental y dirigía con su poderosa voz al camarógrafo. Luego, cuando le entregué un poema que publicaría en Letras Nacionales y me haría un elogio que me mostraría un camino.

Tender puentes entre pueblos negros, entre dos océanos unidos por la historia, fue una labor de dos grandes escritores que hoy, en el ańo del centenario de ambos, recordamos con inolvidable orgullo Pacífico y Caribe. 
BiBLIOGRAFÍA

Bejarano, Alberto. "Figuras del mar en la poesía y el cuento de Helcías Martán Góngora y Carlos Arturo Truque”. Narraciones y experiencias literarias en el Valle del Cauca, Miranda Rojas y G. Zamudio Tobar (eds.), Cali, Editorial Universidad Santiago de Cali, 2020, pp. 48-61.

Martán Góngora, Helcías. Evangelios del Hombre y el paisaje-Humano litoral. Bogotá, Ministerio de Cultura de Colombia (Biblioteca de Literatura Afrocolombiana), 2010.

Múnera, Alfonso (comp.). Manuel Zapata Olivella, por los senderos de sus ancestros. Textos escogidos. Bogotá, Ministerio de Cultura (Biblioteca de Literatura Afrocolombiana), 2010.

Rodríguez, Baquero Luis E. et al. Historia de Colombia. Todo lo que hay que saber. Bogotá, Aguilar, 2011. 